\title{
Bolívar Lamounier. Moinho, esmola, moeda, limão: conversa em família
}

\author{
Anita Waingort Novinsky*
}

São Paulo: Augurium, 2004. 431p.

Com uma obra que vem revolucionar a historiografia brasileira - Moinho, esmola, moeda, limão: conversa em família -, Bolívar Lamounier se lançou numa aventura histórica cujas proporções se estendem da mais profunda fantasia ao mais sério rigor científico.

Num volume de 431 páginas que lemos como se fosse o mais atraente romance, o autor mergulha no passado e fala a todos nós, leigos e historiadores, que buscam encontrar um elo entre o que somos e toda a galeria de antepassados, que não conhecemos, que viveram e lutaram antes de nós, para sobreviver com o trabalho, a caridade, o negócio, as plantas e a natureza.

Inicialmente, Lamounier partiu de um sentimento, uma curiosidade, uma curiosidade que nos preocupa a todos: quem somos? Não apenas como seres biológicos, mas como seres sociais.

Parte então fascinado pelos nomes. O que significam os nomes? E os sobrenomes? Como se formaram? Como evoluíram? Para responder a estas questões o autor penetra fundo no poço da história, vai ao Império Romano, vai à Idade Média, vai às Cruzadas. De onde veio seu nome? Buscou pistas, vasculhou o longínquo passado atravessando a realidade vivida pelos homens, suas lutas para sobreviver, suas misérias, até chegar ao grande tema político a formação dos Estados Nacionais - e a alucinante corrida pela posse das riquezas. Mostra-nos que os apelidos e sobrenomes são derivados de ofícios, e isso é uma constante no mundo; entretanto, esse fenômeno não se verifica na onomástica brasileira durante o período colonial, talvez por causa da escravidão, talvez porque Portugal não permitia o desenvolvimento da colônia, limitada apenas a produzir para o Reino.

Os apelidos, na Europa em geral, têm origem em uma ocupação - que depois se generaliza e se transforma em sobrenome hereditário. Lamounier

\footnotetext{
* Laboratório de Estudos sobre a Intolerância - Universidade de São Paulo (USP). Av. Prof. Lineu Prestes, 159 (prédio da Casa de Cultura Japonesa, subsolo), Cidade Universitária Armando de Salles Oliveira, Butantã. 05508-000 São Paulo - SP - Brasil. anitano@terra.com.br.
} 
foi buscar seus ancestrais, longínquos, que viveram em outro universo, diferente do nosso, e caminhando através da história chega até nós - e até as fantásticas conquistas da técnica, sempre num crescendo até ancorar em Minas Gerais.

Vejamos o caminho percorrido pelo autor: partiu de quatro focos - o moinho, a esmola, a moeda e o limão. Partiu de um mundo onde a identificação das pessoas era precária e incipiente, para o mundo onde a identificação é completamente institucionalizada. Passou de um mundo 'ignominioso', sem nomes, ou de nomes difusos e instáveis, para o mundo atual, onde a identificação individual é minuciosa.

Apresenta-nos então o 'moinho' e a 'miséria', que era percebida como condição imutável, para em seguida chegar à 'moeda', quando se formam os Estados Nacionais, que controlam a fabricação e a circulação do dinheiro - e por último, nos conduz ao 'limão'. Desses quatro focos evolui o mundo na direção do progresso.

Assim, duas visões de mundo se confrontam: uma é hostil à modernidade, nostálgica de um mundo mais simples; outra valoriza as conquistas materiais e a cultura, como caminho para uma vida humana mais feliz.

Lamounier mostra-nos o destino humano em um tempo quando tudo era desígnio divino e inexistia a idéia de progresso. A pobreza era aceita como algo natural e os reinos praticavam a caridade não para ajudar o 'outro', mas para salvar sua própria alma. As esmolas, escreve Lamounier, eram vistas como recibos de depósitos a serem cobrados no céu. Essa visão de mundo se manteve durante séculos.

As restrições religiosas que bloqueavam o progresso científico são quebradas no século XVIII, até que no século XX, depois da Segunda Guerra Mundial, a Igreja passa por um processo de 'esquerdização', principalmente na América Latina, desaguando na Teoria da Libertação.

A industrialização e a modernidade tornaram a sociedade moderna extremamente vulnerável, e o socialismo aumentou ainda mais a centralização e a burocratização do Estado. Talvez, pensa o autor, as organizações não governamentais (ONGs) possam auxiliar na direção de uma nova política social.

Afinal, parece que nos encontramos numa situação angustiante e insolúvel, numa encruzilhada sem saída. De um lado, o mundo melhorou - hoje há muito menos pobres do que há dois ou três séculos. De outro, navegamos num agitado mar de violência destrutiva. Lamounier nos confronta com esse mundo paradoxal e pergunta: qual a saída? 
Do moinho, da pobreza, da esmola, Lamounier passa para a moeda - e tece a mais curiosa história sobre sua origem e progresso. Durante séculos a escassez de moedas de pequeno valor dificultava as transações básicas da vida cotidiana e entravava o desenvolvimento do comércio. A moeda é uma criação recente - e seu desenvolvimento resultou de um processo lento que só se completou em estágio bem avançado do capitalismo. Como meio universal de troca, a moeda é um fenômeno do século XIX. Surgem então os patronímicos derivados da moeda.

Em se tratando de nomes, Lamounier lembra que há um mito corrente, de que os portugueses descendentes dos judeus, os cristãos-novos, traziam nomes de frutos e árvores, como, por exemplo, os Oliveira, Lima, Pereira, Carvalho. É verdade que esses nomes aparecem também entre os cristãos-velhos e em outros países, mas o que surpreende é a constância de alguns deles entre os cristãos-novos.

Sobre a mentalidade que na época predominava entre as elites dirigentes portuguesas, Lamounier nos mostra que estava conectada com a ContraReforma, a Inquisição e o Absolutismo. A falsa aparência de riqueza de Portugal coexistia com o seu obscurantismo - expresso numa instituição de terror, a Inquisição, cujos efeitos sobre a economia e a alma dos homens ainda não foram devidamente analisados.

No momento em que a Europa se reformula com o Iluminismo, quando filósofos expressam e criticam o mundo, a política, a religião, d. João V - chamado de "rei freirático", porque todas as noites ia aos conventos dormir com as freiras - esbanja o ouro brasileiro para ostentar os famosos autos-de-fé, aos quais assistia com verdadeira paixão, rodeado de toda a nobreza.

Não creio que o furor inquisitorial tenha diminuído sob d. João V. Ao contrário, foi durante seu reinado que a Inquisição agiu com maior furor, prendendo e penitenciando centenas de luso-brasileiros, tanto em Portugal como no Brasil. Só fechou suas portas em 1821, continuando porém a existir no século XX, sob o nome de "Congregação para a Doutrina da Fé", da qual foi diretor e ideólogo o atual papa Bento XVI.

Lamounier lembra-nos um aspecto sumamente interessante de nossa vida colonial no século XVII, o mandonismo de nossos fazendeiros de açúcar, que controlavam a Câmara e desacatavam os governantes enviados da Metrópole. Quem na realidade mandava no Brasil eram os senhores de engenho, que tinham verdadeiros exércitos, e os chamados "homens bons", que controlavam todos os setores da vida - os preços, a construção de estradas e a Câmara.

Lamounier sugere uma resposta à questão formulada por Sérgio Buar- 
que de Holanda e que permanece sem resposta até hoje: por que o Santo Oficio da Inquisição nunca estabeleceu um Tribunal no Brasil, se o tiveram México, Cartagena e Peru?

Depois da expulsão dos holandeses e durante a crise do açúcar, Portugal se ergue economicamente com o descobrimento do ouro, e, enquanto o Brasil manda toneladas do metal para Portugal, o povo morre de fome. A metrópole não permitia a livre iniciativa, a criação de uma universidade, nem a existência da imprensa, e proibia qualquer atividade que não fosse a extração do ouro.

O quadro de Minas Gerais que Lamounier nos pinta, revela o desastre da colonização - a Inglaterra enriquecia com o nosso ouro, e Portugal comprava luxo às custas do Brasil. O que impressiona é ler sobre a violência e as crueldades da sociedade mineira - que para o autor são conseqüência do regime absolutista.

Segundo certos autores, quando o ouro acabou, a população de Ouro Preto ficou reduzida - a economia murchou, a população empobreceu, as terras das minas foram abandonadas e surgiu outro tipo de sociedade. Mas Lamounier discorda de Celso Furtado sobre a atrofia econômica de Minas depois da extinção do ouro, e analisa opiniões controversas de diversos autores.

Através da busca curiosa de si próprio, Lamounier se lança na investigação crítica da história, atravessando campos diversos das ciências humanas. Parte da singularidade para chegar ao todo. Às vezes parece esperançoso, às vezes cético.

Como evoluiu a vida material do homem, como progrediu a sociedade, com seus desastres e suas vitórias, com suas cruezas e suas generosidades - e para onde partimos?

Lamounier nos mostra os paradoxos da trajetória humana. De um lado, a luta para preservar o que já está estruturado, de outro a ânsia de mudança. Se de um lado decaímos - pois à medida que evoluímos, evolui a crueldade, a violência, a anti-ética -, de outro, materialmente, quanto progresso e quanta inovação!

Depois de percorrer o mundo, reconstituir o cotidiano, refletir sobre a violência e a crueldade dos homens, os meios de subsistência, os alimentos, a casa, o mobiliário, os costumes, os talheres, as baixelas, as políticas reais e a mentalidade, depois de nos conduzir ao moinho ao século XX, Lamounier volta às suas memórias e origens. Retorna ao século XVIII, quando vivia seu antepassado Afonso Lamounier, que aos 20 anos chega sozinho de Lisboa para a Comarca do Rio das Mortes. O que o trouxe para as Minas? Aventura, ascensão social, 
dinheiro? Ou talvez, quem sabe, o estigma de sua ascendência na sociedade racista de Portugal?

No Brasil, Afonso Lamounier recebe terras e sesmarias, e seu bisneto Lamounier Godofredo faz parte do primeiro Congresso Republicano. Bacharel em Direito, deputado do Império, pronuncia-se enfaticamente sobre a separação entre Estado e Igreja, sobre a liberdade de culto e liberdade de consciência; luta pelo direito do voto feminino, pela reforma salarial e pelo antimilitarismo, participando da Constituinte de 1891.

E ainda outro Lamounier, Gastão Marques Lamounier, cujo talento o levou para a carreira de músico, e o curioso Levindo Lamounier, trineto daquele primeiro jovem que chegou ao Brasil e foi viver no sertão.

É interessante que a 'obra aberta' de Bolívar Lamounier nos mostra diversos caminhos - e nos sugere as mais diversas idéias e considerações. A mais sugestiva que perpassa o pensamento do leitor é, talvez, a sua identificação com a Sobornost, palavra que designa os princípios fundamentais do 'viver russo', pelos quais cada ser humano é visto como uma singularizarão da vida de muitos.

Compreender o ser humano como a singularização de muitos, como nos ensina Gilberto Safra, significa que cada ser humano é a singularização da vida de seus ancestrais, assim como o pressentimento daqueles que ainda virão. Quando estamos frente a alguém, estamos frente à singularização dos ancestrais. Cada indivíduo é único - e é também múltiplo. Não é possível abdicar à condição humana sem pensar o homem através da história. Porque o homem não é só ser natural. É também histórico. A vida de cada um de nós só pode ser percebida na estrutura e forma da nossa própria família. Ao mesmo tempo em que o homem é filho da natureza, é fruto de seus ancestrais.

A obra de Bolívar Lamounier identifica-se com essa concepção de forma magistral. Deu-nos uma lição para repensar quem somos. Escreveu um livro sobre história do Brasil e encontrou o seu próprio lugar nessa história, compartilhando seu destino com os que estão, com os que foram e com os que virão.

Resenha recebida em dezembro de 2007. Aprovada em dezembro de 2007. 